\title{
A day at the museum: An augmented fine-art exhibit
}

\author{
Anne Bationo Tillon*, Eric Marchand, Jean Laneurit, Fabien Servant, Isabelle Marchal, Pascal Houlier \\ Orange Labs - INRIA Rennes - Université de Rennes 1
}

\begin{abstract}
This paper examines how an augmented reality guide can enrich museum visits. The results we obtained form an experiment conducted for a museum exhibit. An ergonomic experimentation has been conducted where real visitors use our augmented reality prototype. We collected feedback from these users, helping us to identify the usefulness of AR for museum visits or appreciation of art work. We conclude this paper by proposing some implications about the future usage of augmented reality in a museum context.
\end{abstract}

KEYWORDS: museum education, experiments, augmented reality handheld device

\section{INTRODUCTION}

Over the last few years, the areas in which augmented reality (AR) is used have expanded to the leisure field, through culture and digital art [1][2]. This paper presents the results of the first experimentation about the French funded ANR GAMME project, which aims to develop a "mobile augmented reality guide for museums and exhibitions". The project was developed using an iterative design method. Museums are a perfect ground for manipulating real objects, yet this implication and manipulation are actually unusual in fine arts museums as opposed to the initiatives of science and contemporary arts museums [3]. More precisely, we are interested on how AR can be used in the field of museum education. The AR system is based on a markerless pose estimation algorithm that is able to register and to track paintings so that no additive markers or sensors should be arranged in the museum. The device is a Samsung Q1 Ultra Premium UMPC. The AR prototype is a tool for the visitor who must fulfill a mission: to help the virtual curator to update the museum collection in specifying the various types of inspiration, the placing of works.

\subsection{Museum educational principles}

We refer to education literature to define the pedagogical objective of the AR museum guide. At first, Dewey [4] aimed at elucidating art experience. From his point of view, perception of art work compels the visitor to create his own experience and to perform as the artist did. In other words, to be able to have a perception of the artwork, a visitor needs to know what has to be seen and how he has to look at the artwork. Goodman [5] remarks that some constraints exist in a museum context: artwork is motionless and congealed. A visitor cannot manipulate artwork, and he tends to think that the creation processes are instantaneous. In order to overcome these constraints, Goodman suggests some principles for museum education. We summarize these principles in Table 1. There is another important dimension underlined by Bruner: the frustration control in order to avoid the loss of motivation [6]. In this research, we used these principles for designing the AR prototype. We aim to improve the next version

\footnotetext{
*e-mail: anne.bationo@orange-ftgroup.com
}

IEEE International Symposium on Mixed and Augmented Reality 2010 Arts, Media, and Humanitites Proceedings

13 -16 October, Seoul, Korea

978-1-4244-9341-8/10/\$26.00 @2010 IEEE of the prototype, in analyzing adequacy between AR characteristics, museum educational principles and visitor experience.

Table 1: Museum educational principles

\begin{tabular}{|l|l|}
\hline Principle 1 & $\begin{array}{l}\text { - isolate some artworks or an area of an artwork } \\
\text { - explicit some models used by artists }\end{array}$ \\
\hline Principle 2 & $\begin{array}{l}\text { - drive visitor's attention } \\
\text { - provoke an active visual survey } \\
\text { - compare finished and unfinished artworks }\end{array}$ \\
\hline Principle 3 & $\begin{array}{l}\text { - underline some characteristics of an art work } \\
\text { (period, signature, style and data about the } \\
\text { artist) }\end{array}$ \\
\hline Principle 4 & $\begin{array}{l}\text { - make interesting juxtaposition between art } \\
\text { works }\end{array}$ \\
\hline
\end{tabular}

\section{AN ERGONOMIC EXPERIMENT}

\section{$2.1 \quad$ Methods}

Sixteen participants were recruited for the experiments (18-25 year old). The museum visit lasted approximately 45 minutes. In each evaluation session, a minimum of 60 minutes was reserved for conducting a post-visit semi-structured interview. Two main types of qualitative data were collected: videos recording the visitor's behavior during the museum visit at the exhibition and narrators' interviews supported by videos and notes collected during the experiments. This is "the agents' contribution to the analysis of their activity".

\subsection{Results}

We have selected some AR functions to examine more precisely educational implications. Our analysis is based on:

- the intentions of designers based on initial principles (Table 1),

- what does the visitor do: we describe some invariant behaviors that we have transcribed from video data,

- the implication for the visitor: we present or summarize some extract of the interviews about the visitor experience,

- the experience improvement: we suggest some directions to avoid visitor frustration and to encourage visitor to look at the artworks with his naked eye.

Let us now detail some of the AR experiments.

\subsubsection{Complementary colors}

Designers' intentions: the aim is to explain the complementary colors' model (principle 1). Visitors have to find the two complementary colors in a painting by Corot to reveal a human presence by manipulating the virtual artwork.

What does the visitor do? First, the visitor is in front of the art work. He is looking at the AR terminal and listens to the virtual curator who explains the complementary colors principles. Second, he clicks on the user interface to reveal dominant color which is green (Figure 1(a)) and the complementary color which is red. Finally, the visitor can modify the different dominant colors (purple or orange) to see that a character at the center of the painting takes the complementary color (Figure 1(b)). 
(a)

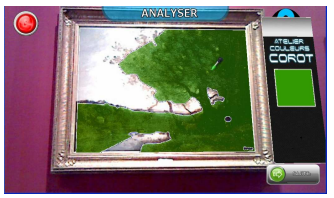

(b)

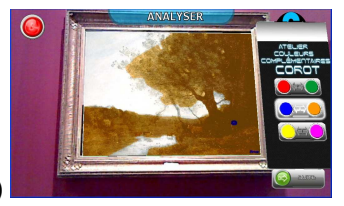

Figure 1: Complementary colors game

Implication for the visitor: some visitors said to us that "it is not that interesting; I prefer to imagine the result with other colors instead of seeing the result on the screen".

Experience improvement: augmented reality is a mean to visualize a model used by the artist into a graphical solution. It provides some direction in order to help the visitor focus on achieving the goal. The part of the game which permits to modify colors is not really successful. We will abandon it in the future. To spur the visitor to revisit the art work with the naked eye, we will ask him what the red color lets underline? The answer is the human presence.

\subsubsection{Pentimento}

Designers' intentions: the game was helping visitors to understand the genesis of the artwork and more precisely to discover a hidden pentimento in the Corot's painting. We tried to provoke an active visual survey thanks to a magnifying glass (principle 2 ). In the center of it, an image is superimposed on artwork showing the pentimento.

What does the visitor do? The visitor contemplates the painting. He moves the magnifying glass on AR terminal exploring the art work. After several seconds, the visitor finds the location of the pentimentos (Figure 2). Then the visitor can discover pentimentos with his naked eye on the painting.

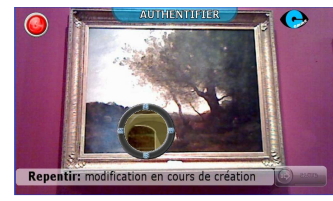

Figure 2: Pentimento game

Implication for the visitor: this game allows motivating visitor's interest and improves crucial points thanks to augmented reality. The visitor's perception of the painting is modified: "without this device, I couldn't see the pentimento".

Experience improvement: in this context, the AR is an instrument which permits to highlight pentimento. In our point of view, this experiment is efficient since there is a shuttle back and forth between the artwork and the prototype. This tool enables visitors to discover some tracks of creation.

\subsubsection{Providing invisible materials}

Designers' intentions: AR permits to see invisible things through the artwork, we used it to reveal the back of the paintings. It was a way to underline some characteristics of the artwork (principle 3). What does the visitor do? The visitor explores the back of the painting with a magnifying glass. He can find the artist's signature or he can read descriptive labels.

Implication for the visitor: visitors' commentaries underline that it's interesting only if they have to find a clue which explains additive information about the story of the artwork. Once they find the clues, they said that it was poor, and they would like to have more information.

Experience improvement: in the future, frustration will be avoided by adding information. The virtual curator will explain some crucial point of the artwork history, and the clues revealed by AR will help visitors to check or to answer a question.

\subsubsection{Superimposing artworks}

Designers' intentions: superimposing images is a good way to surpass difficulties for visitors to compare artworks (principle 4). For the visitor, the goal is then to superimpose an artwork displayed on the museum guide with the corresponding painting in the room of the museum in order to understand the creative process.

What does the visitor do? The visitor is looking at Morrelet's contemporary artwork displayed on the AR prototype (Figure 3(a)). The visitor is attentive to his environment, to the paintings in the room and to the composition of these artworks. He gets a closer look at a Rubens' painting. Then the visitor uses AR to superimpose the Morrelet's painting (on the computer) with the Rubens (in the museum room) (Figure 3(b)). (a)

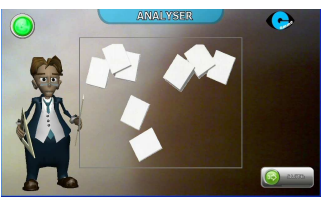

(b)

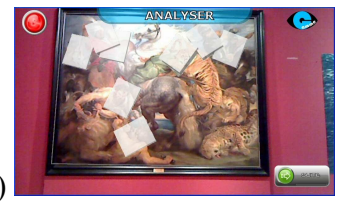

Figure 3: Superimposing art works game
Implication for the visitor: when the visitor finds the target art work, he understands very well the creation process. As one participant said to us: "this game permits me to understand the creation process, the manipulation of this tool reveals it suddenly" Experience improvement: in this context, we think that the game is a good help for the visitor. This AR game is interesting because it provides some directions to the visitors to encourage them to look at artworks in the room with their naked eyes.

\section{Conclusion}

In short, it seems to us that AR is an interesting tool for helping the visitor to do an active visual survey and to identify relevant facts, as well as looking at the artworks in a new insight. Simply put, the AR terminal helps the visitor to understand an artwork that he contemplates. We recommend museum professionals to use AR in the following situations:

- to compare the distinguishing aspects of an artwork with other works (e.g. the composition, colors) thanks to the superimposing function. During a visual survey, the visitor begins to look carefully at the other artworks in a specific way, and then he superimposes the artwork,

- to explore the creation process of a work by indicating the relevant and sometimes hidden details. This will encourage the visitor to revisit, or to look again at the original work,

- to supply visitors with information that are usually accessible only to museum professionals. In these situations, the visitor can learn about the context of art production and about the museum environment, its methods, its operations and the way artworks are incorporated within museums.

\section{REFERENCES}

[1] G. Liestol "Augmented reality and Digital Genre Design- Situated simulations on the iPhone", IEEE ISMAR 2009 AMH Proceedings 19-22 october, Orlando, Florida, USA, pp 29-34.

[2] D. Wagner, D. Schmalstieg, M. Billinghurst, Handheld AR for Collaborative Edutainment. In Z. Pan et al. (Eds.), Artificial Reality and tele-existence. Springer-Verlag Berlin 2006, pp.85-96.

[3] J. Falk and L.D. Dieking, The museum experience. Whalesback books, Washington, USA, 1992.

[4] J. Dewey. Art as experience. Perigee, 2005.

[5] N. Goodman. Of mind and other matters. Harvard Univ. Press, 1987.

[6] J. Bruner. The process of education. Harvard Univ. Press, 1977. 